\title{
Thinking about Constructive Teaching for Military Professional Education
}

\author{
Huafang GENG ${ }^{\mathbf{1}}$, Jianmei DAI ${ }^{\mathbf{2}}$ \\ ${ }^{1}$ Changping N.C.O School, Equipment Academy, Beijing, China \\ ${ }^{2}$ Department of Information Equipment, Equipment Academy, Beijing, China \\ cherry5810@sina.com, benxuelan0402@126.com
}

\begin{abstract}
Military professional education plays a key role in training high qualified military officer, the traditional education ideas has not been meet the requirement of the new military revolution. The problems such as traditional education values, role of teacher and students and teaching content system existing in the military professional education is concluded, the constructive teaching method is elaborated, and the approach to implement the constructive teaching in military professional education is discussed.
\end{abstract}

Index Terms - Constructive Teaching, Military Professional Education, Problem, Implementation

\section{Introduction}

Military professional education is a kind of education which gives knowledge, ability and attitude of the education for the educatees in accordance with the military professional jobs need, its main objects including sergeant students, fulltime education graduates of colleges, and military in-service cadres with strong theoretical foundation and rich practical experience. Compared with the formal schooling education, the purpose of military professional education is stronger, and the request of teaching ideas is stricter.

The traditional education ideas and teaching modes are difficult to support the mission of cultivating high-quality military personnel as the instantaneous change of information in the information society and the high speed of knowledge update. Therefore it is imperative to import the constructive teaching method which is a kind of modern education teaching idea in military professional education.

\section{The Problems Existing in the Military Professional Education}

There are a lot of problems which blocking the development of military professional education, for example: the teaching idea can't keep up with the pace of education teaching practice, teaching content can't keep up with the expansion of the students view, the disciplines, specialties, courses and subject can't fit the construction of troops and the development of military struggle situation, and the improvement of the teaching ability of teachers can't keep up with demand for high quality teachers in the colleges transformation of education and teaching reform of surge velocity.

A. The traditional education values hindering teaching implementation of the professional education

There are some phenomena which are the intangible obstacles for education culture construction that using idea and mode of education with formal schooling to do military professional education during the transition in the current military universities. For example, some colleges and universities are still immersed in pattern in material culture, system culture and spirit culture level, and the setting of education curriculum, teaching implementation, teaching evaluation and so on are the fix of the formal schooling on some level. At the same time, the results oriented education expectations based on the traditional education concept also hinder the constructive teaching implementation. It is a dominant form of teaching effectiveness for teacher to make ranks and grades as the core indicators of student learning.

B. The role of faculty and students status did not meet the requirements of the military professional education

At present, the ideas of "the absolute authority of the teachers" and "teacher-centered" are still rooted in quite a number of faculty in the mind, It leads to the result that the students follows the thinking of faculty in most ways. The problem consciousness is light, the learning initiative and creativity is restrained for many students. It is highly not adapt to military professional education with the "ability standard". The modern teaching theory believes that teachers in the teaching process should play the role of organizer, instructor, helper and promoter, and help learners use learning environment elements such as situation, cooperation, conversation, and effectively realize the current knowledge in "meaning construction" in order to give full play to students' initiative, enthusiasm and initiative; students are the main part of the learning who participate in teaching activities on their own initiatives and are no longer to get the development of general ability, knowledge.

\section{Lessons are not meet with the teaching content system of "Centering on the problem"}

At present, the teaching content set of military college is centered with subject knowledge logic and it cannot meet the demands of students. While the urgent need of modern war is persons who are good at the interdisciplinary knowledge and be able to satisfy the needs of the future joint operations command. The essence of military professional education and the characteristics of comprehensive and practical application of Military discipline require building teaching content system with "centering problem". The military professional education 
is based on the position of post education; the students have a rich experience of forces practice, strong sense of self education and clear study directivity. However, there are prominent contradictions between short time, heavy task, and multiple levels. Therefore, it needs to break the original pattern to restructure the professional disciplines, teachers, and organizations, and the support and guarantee of human, material and financial resources are more urgently needed.

\section{Parsing of Constructive Teaching Ideas Pointing to Military Professional Education}

The constructive teaching in the military professional education idea is developed with the prototype of "constructivism" which is oriented western countries. Students are advocated to be the center in teaching activities and are required to be changed from passive recipients of external stimulation and knowledge infusion object into the main body of information processing, the main body of knowledge significance construction, and the faculty members are required to be changed from imparter of knowledge into the helper and facilitator for students' actively construct.

\section{A. The constructive education emphasizes student centering}

The idea of constructive teaching philosophy of military professional education is that the leaning purpose of students is to meet the needs of their own knowledge by discovery method and exploring method. In the process of learning, students' initiative to collect and analyze relevant information and data is stimulated, and they can put forward assumptions on the issue of learning and try to verify by themselves. They can do self-monitoring, self-test, self-examination, judgment or test their learning behavior in the process of learning to achieve the desired effect. Constructive teaching emphasizes the central position of the students and the counseling, guidance, and support role of teachers in the learning activities.

\section{B. The constructive education is practical, authenticity and initiative}

Students could process, generate their own experience, interpretation, hypothesis to get its own meaning construction with new things, new phenomena and new problems, new information and external information according to their own experience background. Students can discuss with other students or consult faculty if they encounter problems, students are in close contact with others throughout the learning process. Students are in a certain, complex, real learning environment, and through the positive action or activity to participate in the learning process which can give them full play to their initiative.

\section{The constructive education is guide objective, cumulative and constructive}

Students set learning goal themselves, study the current content associated with previous learning content guided by the goals, process the new information associated with the other information, and maintain the simple information to understand more complex information. The learning behavior is considered to be success only when students experience hard efforts and achieve the learning goals.

\section{Implementation Ways of Constructive Teaching Methods in Military Professional Education}

The military professional education is in the critical period of transition, and advocating constructive teaching has the unusual significance. The constructive teaching should use the teaching design, teaching content system and teaching methods of "Centered on practical problems traction" in the process of teaching for the vocational and comprehensive nature of the military education characteristic and the practical and applicability features of military discipline.

\section{A. Constructive teaching needs students' questioning consciousness}

Constructive teaching point for military professional education is not only to improve the ability of students to understand the knowledge, but also to cultivate the ability of students to find the problem, analyze and solve problems, and must pay attention to training students' questioning mind. First, it is necessary using problem to guide the whole teaching process. Differing from knowledge teaching, Constructive teaching is to guide students find all sorts of problems and the spiral, interdependence and mutual connection relationship between the problems, at the same time let students bring more problems out of the classroom and extended to extracurricular, and stimulate the students' autonomous learning awareness. Second, students' critical spirit should be cultivated. Faculty should set apart time for learners to think in the teaching process, encourage the spirit of independent thinking, and allow them to have different opinions and ideas. The answer to the question provided by faculty members is not the only one which lets students to find and solve problems themselves and makes students form the spirit of questioning, criticism, exploring and creating.

\section{B. Constructive teaching needs teaching content system with "Centered on realistic subject"}

The Constructive teaching needs to build the teaching content system with "Centered on realistic subject" to achieve the goal of military professional education. The goal is training the innovative persons with high quality of technology who can meet the requirement of jobs, and know how to command and management. To solve the realistic subject in military forces, the core of the teaching content system with "Centered on realistic subject" should break the traditional disciplinary knowledge fragmentation and restructure the knowledge system. It needs to integrate various knowledge to design synthetic courses, and find breakthroughs in interdisciplinary, overlapping, to foster a strong innovation consciousness and ability of comprehensive knowledge. The realistic subject knowledge is reorganized and the practicalness and variability are emphasized in the teaching content system with "Centered on realistic subject". Teachers can proposition according to the current hot issues in the military field or the new missions in 
the new stage, such as how to finish the diverse array of military tasks, how to construct the information army, how to win the information-based war, and how to command under the complex electromagnetic environment battle and so on. The change of the teaching content system determines that the learning process of students will be implemented from simple to complex and the learning process will be changed from low level to high level. Students can assimilate or comply with the original knowledge system to optimize the structure of selfknowledge under the guidance of faculty members.

\section{Constructive teaching needs diversified teaching methods}

There is no fixed way for teaching. The teaching methods of constructive teaching in military college must implement from teaching to guiding. Faculty and students must discuss and collide with each other for stimulating the students' intrinsic motivation and potential of thinking and improving the level of thinking and innovative ability constantly. Reasonable and diversified teaching method is an accelerator to prompt the transformation of students from knowledge to ability. There are variety of teaching methods should be tried, such as: Discussion-based teaching method, question-andanswer teaching method, discovery teaching method and practice teaching method, etc. Discussion-based teaching method emphasizes the faculty's careful preparation and guidance, the faculty should design and organization in advance to achieve certain teaching goals including inspiring students' opinions on specific issues and cultivating students' independent thinking ability and innovation spirit. Questionand-answer teaching method emphasizes the interactive relationship between faculty and students, the students should answer the question faculty proposed, and faculty should explain and illustrate in view of the problems existing in the students' answer. In order to make students obtain their sense of self-confidence and interest in learning, discovery teaching method requires that faculty members should do a small amount, keep some new knowledge similar to the old knowledge as far as possible, and guide the students to find. Practice teaching method which is a kind of theory with practice teaching method emphasizes the students' ability of operation; the students understand the theoretical knowledge in practice.

\section{Conclusions}

The constructive teaching should be import in military professional education. The paper concludes the problems existing in the military professional education including traditional education values, role of teacher and students and teaching content system, elaborates the constructive teaching method, and discussed the approach to implement the constructive teaching in military professional education. It is sure that the modern teaching methods with more era characteristics should be introduced, and the traditional teaching method with military characteristics should be put to good use too.

\section{References}

[1] Yingjiu Liu, Guoping Xing, and Zhiqinag Zhang. Military academy education and teaching theory. National defense university press. 2008.

[2] HengZhang Tu. Military professional education theory. Military science press. 2007.

[3] Yutian Pan, ShiXin Geng. Military academy education theory. Tides publishing house. 2006.

[4] Yuankui Li, Lifeng Ma. Research on Military academy education. Tides publishing house. 2005.

[5] Jieyi Yang, Zhaohai Chen, Zengyin Zhang. Military academy education reality problem research. Tides publishing house. 2010.

[6] Yue Li, Xiaomeng Wang. Introduction to "constructivism" application in military school education. Vol of Education cognition and practice to explore transformation theory. 2007:427-433.

[7] Xiaogong Zhang, Zhijie Zhang. Rethinking of Strengthen for education practical teaching. Chinese military education. 2010 (12): 34 and 35.

[8] Yingjiang Liao, Bin Ding. Focus position requirements; improve the quality of education. Northwest military. 2010 (4): 81-82. 